\title{
WhatsApp in mHealth: an overview on the potentialities and the opportunities in medical imaging
}

\section{Daniele Giansanti}

Technology and Health Department, National Institute of Health, Rome, Italy

Correspondence to: Daniele Giansanti. Technology and Health Department, National Institute of Health, Rome, Italy. Email: gianslele@gmail.com.

\begin{abstract}
WhatsApp as many other Messaging Apps or "Messengers" enables messaging and exchanging documents and/or multimedia element (images, movies, music) through chat like tools; these last characteristics makes WhatsApp useful for the remote-image exchanging in $m$ Health for teleconsulting. Among the other potentialities of this App there are (I) the possibility to create groups, the so called WhatsApp Groups and (II) the possibility of this App to be installed into a platform based on a personal computer through the version for pc named WhatsApp Web; these potentialities allow both the creation of protected groups for cooperative teleconsulting and the creation of client-server architectures in telemedicine and e-Health. Scholars have recently shown the usefulness of WhatsApp in several mHealth applications. Recent important studies are highlighting, for example, the wide-range opportunities of WhatsApp as an adjunctive tool in mHealth in medical imaging or in specific applications such as in oral medicine in orthopedics and tele-education. In this contribution we share our alignment with these scholars and presents our polarities of research in the use of WhatsApp. These polarities range from the institutional surveillance of the spontaneous phenomena of WhatsApp groups in the families for the monitoring of the fragile patient up to the test of use of WhatsApp in digital-pathology and digital-radiology static imaging and recently in cardiologic dynamic imaging.
\end{abstract}

Keywords: $m$ Health; smartphone; medical images

Received: 22 August 2019; Accepted: 25 October 2019; Published: 05 April 2020.

doi: 10.21037/mhealth.2019.11.01

View this article at: http://dx.doi.org/10.21037/mhealth.2019.11.01

\section{Introduction}

In a recent scientific contribution Williams and Kovarik respectively from Ministry of Health of Botswana, Gaborone, Botswana and from the Department of Dermatology, Perelman School of Medicine entitled "WhatsApp: An Innovative Tool for Dermatology Care in Limited Resource Settings" (1) faced the overcoming usefulness of WhatsApp in some applications of Medical Imaging such as the Dermatology care opening a scientific interesting discussion.

In particular this contribution:

(I) Firstly, commented the perspectives and the opportunities of WhatsApp highlighted in the Mars and Scott article "Being Spontaneous: The Future of Telehealth Implementation?” published in September 2017 (2) asserting how the faced topic was forward thinking, innovative, realistic, and in alignment with authors' experience on the ground in Botswana.

(II) Secondly, shared the authors' position and experience using WhatsApp for dermatology care in Botswana, and explained how this application can be easily adapted and integrated into clinical practice in resource-limited settings to improve patient outcomes.

The opportunities of WhatsApp have been strongly remarked in the two contributions $(1,2)$. Also other recent important studies are highlighting, for example, the widerange opportunities of WhatsApp as an adjunctive tool in $m$ Health (3) or in specific applications such as in oral medicine (4) in orthopedics (5) and tele-education (6). 
Very rare are the cases of experiences don't creating heath management improvements, as in a case of an application of the management of blood donors (7); furthermore several WhatsApp updates since the 2016/2017 up to now allowed the overcoming most of the few limitations reported by the authors (1).

\section{Purpose of the contribution}

The objective of this contribution is to share our alignment with the position of Williams and Kovarik (1) towards the presentation of our research activity moving around WhatsApp at the Istituto Superiore di Sanità (ISS) through several polarities of research. These polarities range from the institutional surveillance of the spontaneous phenomena of WhatsApp groups in the families for the monitoring of the fragile patient up to the test of use of WhatsApp in digital-pathology and digital-radiology static imaging and recently in cardiologic dynamic imaging.

\section{WhatsApp in mHealth: the potentialities}

Messaging Apps or "Messengers" are Apps and platforms that enable messaging and exchanging documents and/or multimedia element (images, movies, music) through chat like tools. The alternatives are many and among the most known we find: Hangouts; Telegram; Whatsapp; Facebook Messenger; Viber; Skype; Tango; OoVoo; Snapchat; WeChat; Yahoo Messenger. Not all, however, have the same success. WhatsApp (Facebook Corp, USA) instant messenger is one of the most diffused ones and allows the quickly sending messages on your mobile phone to any contact on your contacts list in the phone. Obviously the only requirement is that people involved in the network must have the APP installed on their own device. Currently, WhatsApp is compatible with just about all mobile operating systems on the market: Android, iOS, Symbian and Windows Phone. This basically means you are able to use WhatsApp to communicate with anyone, regardless of what model of device they have. WhatsApp users can send text messages, voice messages, links multimediafiles (images, movies, music) to any other user; these last characteristics makes WhatsApp useful for the remoteimage exchanging in $m$ Health for teleconsulting. Among the other potentialities of this App there are (I) the possibility to create groups, the so called WhatsApp Groups (WAGs), and (II) the possibility of this App to be installed into a platform based on a personal computer through the version for pc named WhatsApp Web; these potentialities allow both the creation of protected groups for cooperative teleconsulting and the creation of client-server architectures in telemedicine and e-Health. The opportunities of WhatsApp have been strongly remarked in in the previously cited contributions (1-6).

\section{WhatsApp in mHealth: the position and the study at the ISS}

We: (I) found the Williams and Kovarik contribution (1) current, interesting and timely to open a debate among the $m$ Health scholars and stake-holders especially, considering also that it is a position paper from a governmental institution (the Ministry of Health of Botswana); (II) are certainly also aligned with the same position of William and Kovarik. Our specific position of alignment with (1) in regards to the opportunities of WhatsApp comes directly from our governmental experience at the ISS (The Italian $\mathrm{NIH}$ ) in the Centre of innovative technologies in public health. This experience is directed into two directions both with an institutional and a research point of view.

The first direction is to face, with a careful consideration as an active observer, the emerging experiences of the use of WhatsApp as a spontaneous tool in familiar mobilenetworks dedicated to the management and monitoring of fragile subjects in domiciliary care. Here WhatsApp is used as a means to H24 connect in specific WAGs (Figure 1) the familiars, the familiar care-givers, the non-familiar caregivers (as for example the salaried ones), other health care (HC) actors (as for example the Italian family doctor). This was recorded in recent conferences at the ISS dedicated to the technological innovations in the monitoring of the fragility (8); the role of the ISS is clearly to monitor with attention as active observer these experiences also in consideration of the regulations $(9,10)$.

The second direction is focused to the application of WhatsApp in the medical-images exchanges. In particular the two field of interest which are receiving special attention are:

* The digital pathology (DP), with the two components, digital cytology and digital histology, in consideration to the diffusion of these technologies from PC-based application (11) to the mobile-health applications $(12,13)$.

* The digital radiology (DR), embedding all the DICOM compliant (14) diagnostic systems.

We have designed specific studies with working 
groups (WGs) comprehending all the actors on the use of WhatsApp in these fields. Both in DP and in DR we are assisting to positive feedback from actors in the WGs, as highlighted on the specific assessment by means of dedicated surveys in DP (15) and in DR $(16,17)$. Figure 2 shows some steps of application of WhatsApp in the critical sector of DP represented by the digital cytology (18).

In DR, where the use of PACS $(16,17)$ is well ruled and standardized, it was found particularly useful the potentiality of WhatsApp Web (Figure 3) as a means to be installed in the server (i.e., the platform with the PACS) to send images from here to the remote teleconsulting sites.

\section{Work in progress at the ISS: WhatsApp and the dynamic images}

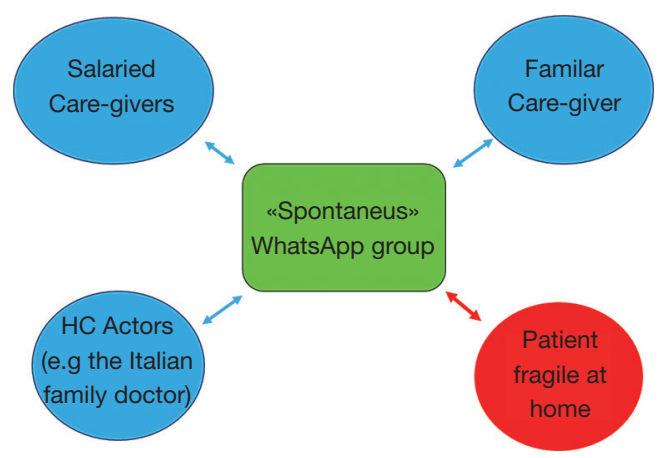

Figure 1 Example of spontaneous WAG in the domiciliary monitoring. WAG, WhatsApp Group.
The next step will be focused to:

(I) The specific design and application of technology assessment $(19,20)$ in these fields of DR and DP of $m$ Health, also using the TAM models (21). At the moment we are completing some of these studies, widening of the cited studies (15-17) and proceeding into the dissemination.

(II) The broadening of the studies in the field of dynamic images in DR. In the diagnosis in this field it plays an important role the visualization of the image kinematics, while the image resolution is still important but less critical. In particular we have focused to the hemodynamics and echocardiography. A first problem that we had to solve was the integration of such images into WhatsApp Web; in fact the PACS are able to provide files converted from DICOM into AVI format; but this format is not compatible with WhatsApp Web which accepts only specific versions of MP4. The "egg of Columbus" was represented by the decision to not convert the AVI into an MP4 file; but to store the AVI directly into a cloud and to export the link pointing to the file. This avoided complex conversions by simply exchanging the internet link using WhatsApp but without using its "attachment functions".

The reader can open by herself or himself these two links relate to one hemodynamic study and to one echocardiographic study and copy them into WhatsApp to try: https://drive.google.com/file/d/1 rsge 5 p 7 N3XJBpn8v_1QVU_6_hBvfsYf/view? usp=sharing

https://drive.google.com/file/d/1V1aMvPXr9p6-
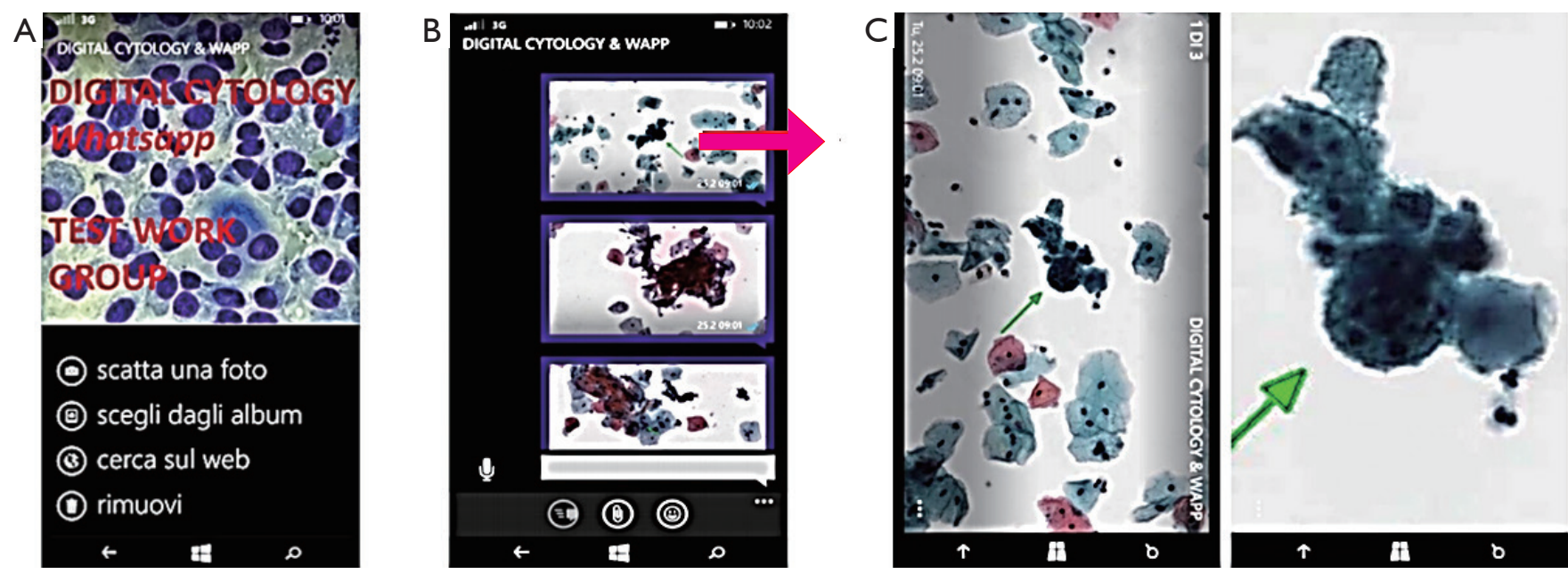

Figure 2 Print screens from the properly designed Workgroup. (A) The workgroup in a critical sector of DP: the digital cytology; (B) an example of virtual navigation finger based; (C) the finger-based magnification of a detail indicated by the green arrow. DP, digital pathology. 


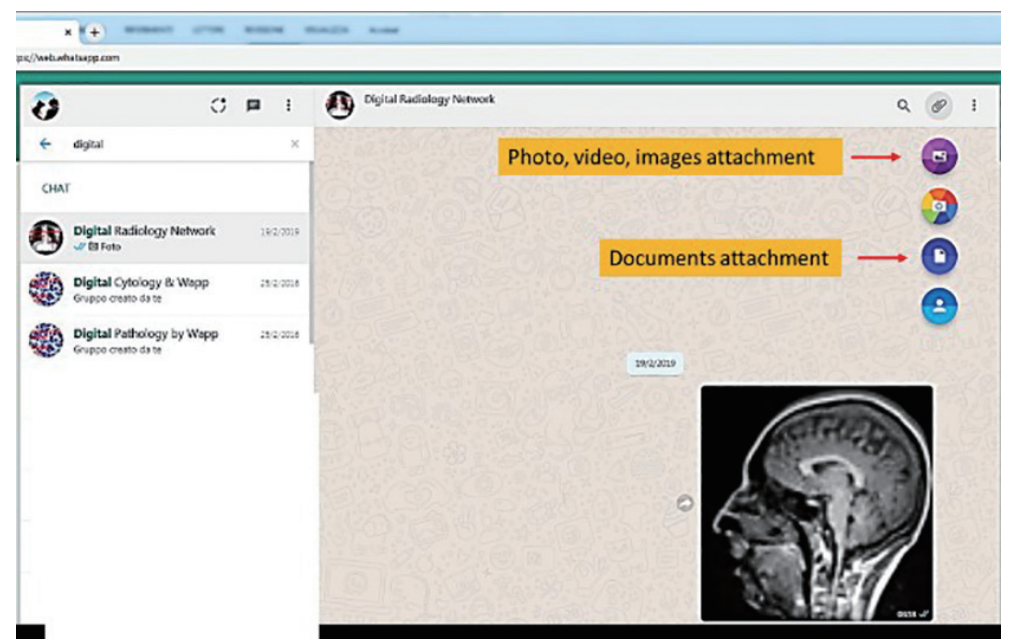

Figure 3 WhatsApp Web: useful at the server side in teleconsulting.

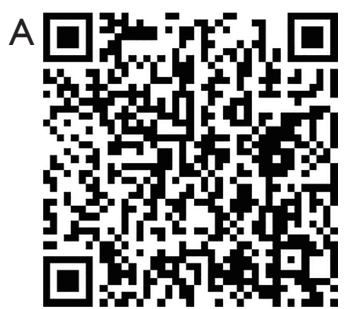

Figure 4 The QR codes relevant to: (A) a hemodynamic study; (B) an echocardiographic study.
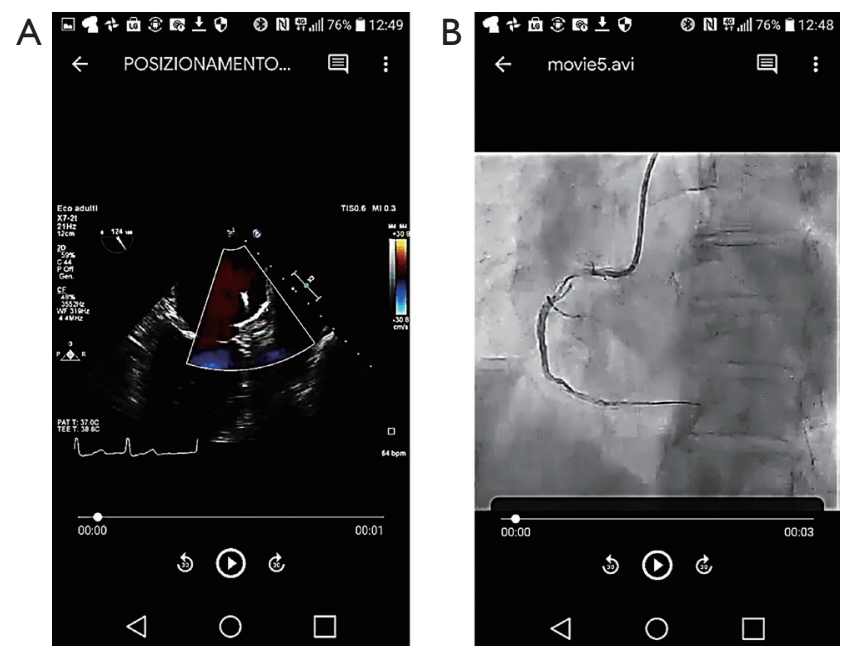

Figure 5 Opening by means of WhatsApp: (A) the echocardiographic study; (B) the hemodynamic study.
3owWnrzcQ_4Piw3JUKY3/view? usp=sharing

In alternative Figure 4 shows the 2 QR codes, useful to extract the links by smartphone. Figure 5 shows two snapshots from smartphone of the two studies. Surely also these studies will follow a road map comprehending the technology assessment and the use of a TAM model (19-21), as for the static images in (1).

\section{Acknowledgments}

Funding: None.

\section{Footnote}

Conflicts of Interest: DG serves as an unpaid editorial board member of mHealth from May 2019 to Apr. 2021.

Ethical Statement: The author is accountable for all aspects of the work in ensuring that questions related to the accuracy or integrity of any part of the work are appropriately investigated and resolved.

Open Access Statement: This is an Open Access article distributed in accordance with the Creative Commons Attribution-NonCommercial-NoDerivs 4.0 International License (CC BY-NC-ND 4.0), which permits the noncommercial replication and distribution of the article with 
the strict proviso that no changes or edits are made and the original work is properly cited (including links to both the formal publication through the relevant DOI and the license). See: https://creativecommons.org/licenses/by-ncnd/4.0/.

\section{References}

1. Williams V, Kovarik C. WhatsApp: An Innovative Tool for Dermatology Care in Limited Resource Settings. Telemed J E Health 2018;24:464-8.

2. Mars M, Scott RE. Being spontaneous: The future of telehealth implementation? Telemed J E Health 2017;23:766-72.

3. Giordano V, Koch H, Godoy-Santos A, et al. WhatsApp Messenger as an Adjunctive Tool for Telemedicine: An Overview. Interact J Med Res 2017;6:e11.

4. Petruzzi M, De Benedittis $M$. WhatsApp: a telemedicine platform for facilitating remote oral medicine consultation and improving clinical examinations. Oral Surg Oral Med Oral Pathol Oral Radiol 2016;121:248-54.

5. Ellanti P, Moriarty A, Coughlan F, et al. The Use of WhatsApp Smartphone Messaging Improves Communication Efficiency within an Orthopaedic Surgery Team. Cureus 2017;9:e1040.

6. Coleman E, O'Connor E. The role of WhatsApp ${ }^{\circledR}$ in medical education; a scoping review and instructional design model. BMC Med Educ 2019;19:279.

7. Rodrigues Lucena TF, Negri LQ, Marcon D, et al. Is WhatsApp Effective at Increasing the Return Rate of Blood Donors? Telemed J E Health 2019. [Epub ahead of print].

8. Summary of congress "Technologies to support fragility and disability" Roma, 21-22 maggio 2018, Notiziario dell'Istituto Superiore di Sanità, Volume 31 - Numero 10, Ottobre, 2018:17-9.

9. Giansanti D. Introduction of Medical Apps in Telemedicine and e-Health: Problems and Opportunities. Telemed J E Health 2017;23:773-6.

10. Censi F, Mattei E, Triventi M, et al. Regulatory frameworks for mobile medical applications. Expert Rev Med Devices 2015;12:273-8.

doi: $10.21037 /$ mhealth.2019.11.01

Cite this article as: Giansanti D. WhatsApp in mHealth: an overview on the potentialities and the opportunities in medical imaging. mHealth 2020;6:19.
11. Giansanti D, Castrichella L, Giovagnoli MR. The design of a health technology assessment system in telepathology. Telemed J E Health 2008;14:570-5.

12. Giansanti D, Pochini M, Giovagnoli MR. Integration of tablet technologies in the e-laboratory of cytology: a health technology assessment. Telemed J E Health 2014;20:909-15.

13. Giansanti D, Pochini M, Giovagnoli MR. How tablet technology is going to change cooperative diagnosis in the cytology e-laboratory. Telemed J E Health 2013;19:991-3.

14. Giansanti D. Teleradiology Today: The Quality Concept and the Italian Point of View. Telemed J E Health 2017;23:453-5.

15. Giansanti D, Palozzi AM, Giovagnoli MR. WhatsApp in digital cytology teleconsulting: a preliminary assessment. In: Giansanti D. editor. Digital cytology: an experience with image-enhancement and tablet technologies. Roma: Istituto Superiore di Sanità; 2016. (Rapporti ISTISAN 16/46).

16. Giansanti D, Cosentino L, Maccioni G, et al. Use of WhatsApp in digital radiology: preliminar considerations. In: Giansanti D. editor. Diagnostic imaging and e-health: standardization, experiences and new opportunities. Roma: Istituto Superiore di Sanità; 2017. (Rapporti ISTISAN 17/10) (in Italian).

17. Available online: https://www.convegnonazionaleaiic.it/ whatsapp-unindagine-sulle-prospettive-di-utilizzo-inradiologia-digitale/ (last access "date of submission").

18. Giansanti D, Grigioni M, D'Avenio G, et al. Virtual microscopy and digital cytology: state of the art. Ann Ist Super Sanita 2010;46:115-22.

19. Giansanti D, Morelli S, Macellari V. Telemedicine technology assessment part II: tools for a quality control system. Telemed J E Health 2007;13:130-40.

20. Giansanti D, Morelli S, Macellari V. Telemedicine technology assessment part I: setup and validation of a quality control system. Telemed J E Health 2007;13:118-29.

21. Rahimi B, Nadri H, Lotfnezhad Afshar H, et al. A Systematic Review of the Technology Acceptance Model in Health Informatics. Appl Clin Inform 2018;9:604-34. 